\title{
Mechanism of the Central Effects of Dopamine and Metoclopramide on Aldosterone Regulation in the Rat
}

\author{
Hiroshi KaWABE, Kazuoki KONDO*, Matsuhiko HAYAShi, Masaki \\ FUJIMAKI, SHUSAKU NAGAHAMA aND TAKAO SARUTA \\ Department of Internal Medicine, School of Medicine, Keio University, \\ Tokyo 160, and Department of Clinical Pharmacology, \\ Jichi Medical School, Tochigi* 329-04
}

\begin{abstract}
To investigate the mechanism of the central action of dopamine and its antagonist, metoclopramide, on the regulation of aldosterone, studies were performed in 54 conscious rats with and without bilateral nephrectomy. In normal and sham-operated rats, intracerebroventricular injection of dopamine resulted in a significant suppression of plasma renin activity and plasma aldosterone at $30 \mathrm{~min}$, and intracerebroventricular injection of metoclopramide resulted in a significant elevation of plasma renin activity and plasma aldosterone at $30 \mathrm{~min}$ without altering the plasma corticosterone and potassium levels. In bilaterally nephrectomized rats, the plasma renin activity was significantly reduced and it did not respond to dopamine or metoclopramide. In these rats, intracerebroventricular injection of metoclopramide exerted no effect on the plasma aldosterone, but intracerebroventricular injection of dopamine increased the plasma aldosterone slightly. However, this increase was not statistically significant.

These findings suggest that the dopaminergic system in the brain is involved in the regulation of aldosterone secretion, mainly with changes in the peripheral reninangiotensin axis in rats.
\end{abstract}

Dopamine is well known as a neurotransmitter substance in the central nervous system (Hornykiewicz, 1966) as well as in the peripheral autonomic nervous system (Thorner et al., 1975). However, the interaction between the dopaminergic system and the peripheral renin-angiotensin-aldosterone system is still not precisely delineated.

During the past few years, intravenous administration of metoclopramide, a competitive antagonist of dopamine (Dolphin et al., 1975), has been shown to stimulate aldosterone secretion in man (Norbiato et al., 1977; Carey et al., 1979; 1980; Noth et $a l ., 1980)$ and in experimental animals (Sow-

Received May 27, 1983 ers et al., 1980a and b; 1981; Kondo et al., 1981a and b). These studies also demonstrated that the increase in plasma aldosterone cannot be attributed to increased levels of any known regulators of aldosterone or to an increase in prolactin. Although it has been found that metoclopramide acts in the central nervous system (Pinder et al., 1976; Peringer et al., 1976) and alters the secretion of several pituitary hormones (Kamberi et al., 1970; McCallum et al., 1976; Scanlon et al., 1977), little is yet known concerning the role of the central dopaminergic mechanism in the regulation of the peripheral renin-angiotensin-aldosterone system. Sowers et al. (1980a) recently reported that the peripheral administration of meto- 
clopramide in bilaterally nephrectomized rats showed an aldosterone response, and they concluded that the effect of metoclopramide by this route on aldosterone secretion may not be mediated by the peripheral reninangiotensin system. However, the precise role of the peripheral renin-angiotensin system in mediating the central dopaminergic control of aldosterone secretion in experimental animals has not yet been determined.

In the present study, therefore, we investigated the effects of intracerebroventricular injection of dopamine and metoclopramide on aldosterone secretion in conscious rats with and without bilateral nephrectomy, and attempted to delineate the central dopaminergic control of aldosterone in rats.

\section{Materials and Methods}

\section{Experimental procedure}

All experiments were performed on male Wistar rats, weighing around $300 \mathrm{~g}$. The animals were divided into 3 groups, as follows: Group 1 comprised normal rats $(n=18)$. Group 2 underwent bilateral nephrectomy under ether anesthesia at $10 \mathrm{hr}$ prior to the injection of drugs $(n=18)$. In Group 3, as a sham-operation, the bilateral kidneys were exposed through a dorsal midline incision $(n=18)$.

In all rats, a $0.11 \mathrm{~mm}$ polythene cannula was placed into the carotid artery, led subcutaneously out through an incision behind the back and filled with heparin $/ 0.9 \%$ saline solution. Insertion of the catheter was carried out under ether anesthesia 1 day before the experiment.

A 21-gauge cannula was implanted at the bregma, $1.3 \mathrm{~mm}$ lateral to the midline, and fixed to the skull with dental cement. The guide cannula penetrated $4 \mathrm{~mm}$ below the surface of the skull and a 27-gauge stylet kept the cannula patent. Implantation of a cerebroventricular catheter was performed under ether anesthesia 2 days before the experiment. The intracerebroventricular injection of the drug was performed in the conscious and unrestrained state.

The drugs used were dopamine hydrochloride (Sigma) and metoclopramide (Fujisawa). These drugs were dissolved or diluted in $0.9 \%$ saline, and the $\mathrm{pH}$ and osmotic pressure of the final solutions were adjusted to 7.0 and $300 \mathrm{mosmol} / 1$, respectively. These solutions were prepared just before injection, and the total volume of the intracerebroventricular injection was always $10 \mu 1$.

In each of the 3 groups, 6 rats were given dopa- mine $(100 \mu \mathrm{g} / \mathrm{kg}), 6$ rats were given metoclopramide $(50 \mu \mathrm{g} / \mathrm{kg})$, and the remaining 6 rats were given an equal volume of $0.9 \%$ saline with blood sampling and volume replacement as in the other rats. Blood samples were taken into chilled test tubes prior to and at $30 \mathrm{~min}$ after the intracerebroventricular injection of the drugs, through the implanted catheter in the carotid artery. $0.9 \%$ saline was administered after sampling in order to replace the depleted volume.

\section{Analytical methods}

Plasma aldosterone was determined by a direct radioimmunoassay (Ogihara et al., 1977), and the intraassay and interassay variation was 7.0 and $7.4 \%$, respectively. Plasma renin activity was measured by the method of Haber et al. (1969), and the intraassay variation was $6.4 \%$. Plasma corticosterone was also determined by radioimmunoassay after chromatographic separation on a Sephadex LH-20 column (Salmenperä and Kahri, 1976). The recovery rate of the hormone by this method was $70 \%$. The intraassay variation was $12 \%$, and the interassay variation was $10 \%$ for plasma corticosterone. Plasma sodium and potassium were measured with a flame photometer.

Six experiments were performed in each study. All values were expressed as means \pm SD. Statistical comparisons were made by using Student's $t$-tests.

\section{Results}

\section{Effects of intracerebroventricular injection of} dopamine and metoclopramide in normal rats:

The intracerebroventricular injection of dopamine suppressed both plasma renin activity $(\mathrm{P}<0.02)$ and plasma aldosterone $(P$ $<0.01$ ) (Fig. 1). The intracerebroventricular injection of metoclopramide stimulated both plasma renin activity $(\mathrm{P}<0.01)$ and plasma aldosterone $(\mathrm{P}<0.01)$ (Fig. 2). There were no significant changes in plasma renin activity and plasma aldosterone in the rats into which $0.9 \%$ saline was injected intracerebroventricularly. Among the 3 groups, there were no significant differences in the basal values of plasma renin activity and plasma aldosterone. Neither dopamine nor metoclopramide, when injected intracerebroventricularly, produced any significant changes in the plasma sodium, potassium and corticosterone levels (Table 1). 

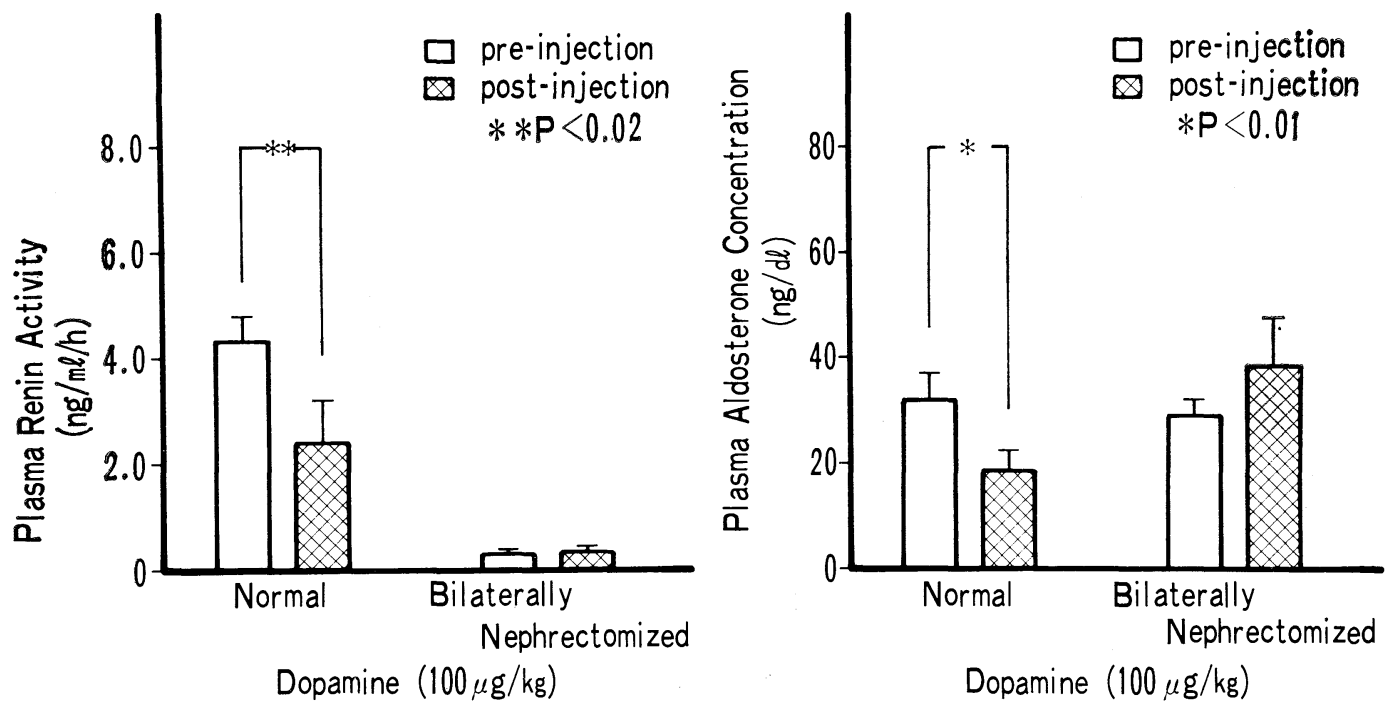

Fig. 1. Effects of intracerebroventricular injection of dopamine on plasma renin activity and plasma aldosterone in both normal and bilaterally nephrectomized rats. The bars indicate SD.
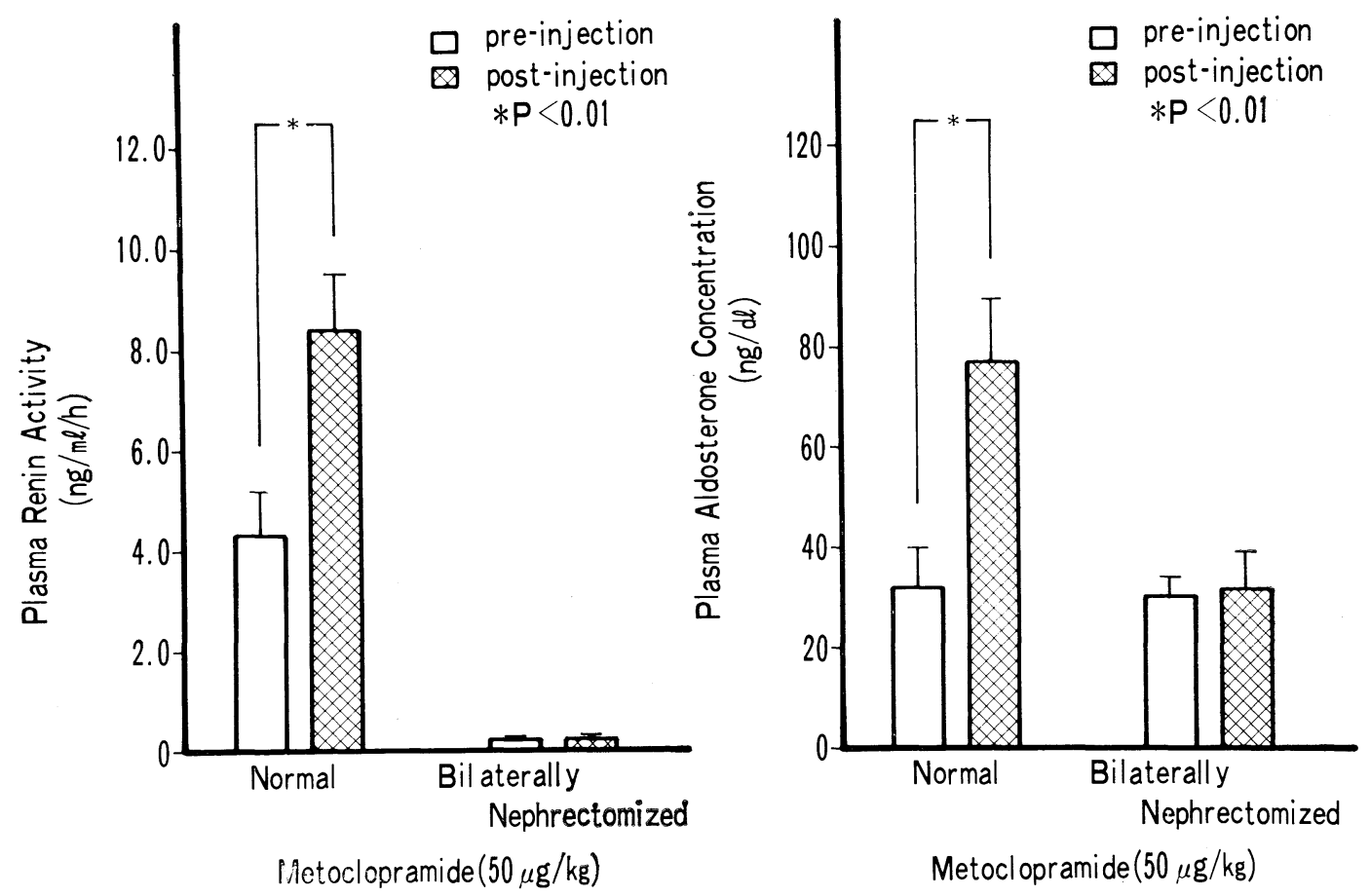

Fig. 2. Effects of intracerebroventricular injection of metoclopramide on plasma renin activity and plasma aldosterone in both normal and bilaterally nephrectomized rats. The bars indicate SD. 
Table 1. Effects of intracerebroventricular injection of dopamine and metoclopramide on plasma sodium, potassium and corticosterone levels.

\begin{tabular}{|c|c|c|c|c|c|c|c|}
\hline \multirow[t]{2}{*}{ Rats } & \multirow[t]{2}{*}{ Treatment } & \multicolumn{2}{|c|}{$\begin{array}{l}\text { Plasma sodium } \\
(\mathrm{mEq} / 1)\end{array}$} & \multicolumn{2}{|c|}{$\begin{array}{l}\text { Plasma potassium } \\
(\mathrm{mEq} / 1)\end{array}$} & \multicolumn{2}{|c|}{$\begin{array}{l}\text { Plasma corticosterone } \\
(\mathrm{ng} / \mathrm{ml})\end{array}$} \\
\hline & & Pre & Post & Pre & Post & Pre & Post \\
\hline \multirow[t]{3}{*}{ Normal } & $\begin{array}{l}\text { Dopamine } \\
\qquad(100 \mu \mathrm{g} / \mathrm{kg})\end{array}$ & $138 \pm 5$ & $135 \pm 3$ & $3.8 \pm 0.3$ & $4.1 \pm 0.5$ & $9.7 \pm 2.9$ & $10.8 \pm 1.9$ \\
\hline & $\begin{array}{l}\text { Metoclopramide } \\
(50 \mu \mathrm{g} / \mathrm{kg})\end{array}$ & $140 \pm 2$ & $135 \pm 5$ & $4.1 \pm 0.2$ & $4.0 \pm 0.3$ & $11.1 \pm 4.3$ & $12.5 \pm 1.7$ \\
\hline & Saline & $140 \pm 2$ & $138 \pm 2$ & $4.2 \pm 0.2$ & $4.1 \pm 0.2$ & $10.8 \pm 1.3$ & $11.1 \pm 0.6$ \\
\hline \multirow{3}{*}{$\begin{array}{l}\text { Bilaterally } \\
\text { Nephrectomize }\end{array}$} & $\begin{array}{l}\text { Dopamine } \\
\mathrm{d} \quad(100 \mu \mathrm{g} / \mathrm{kg})\end{array}$ & $137 \pm 3$ & $135 \pm 6$ & $6.3 \pm 0.3^{*}$ & $6.0 \pm 0.3$ & $12.9 \pm 2.4$ & $12.4 \pm 2.5$ \\
\hline & $\begin{array}{l}\text { Metoclopramide } \\
(50 \mu \mathrm{g} / \mathrm{kg})\end{array}$ & $136 \pm 2$ & $133 \pm 2$ & $6.1 \pm 0.3^{*}$ & $5.9 \pm 0.4$ & $10.4 \pm 1.3$ & $13.1 \pm 1.3$ \\
\hline & Saline & $140 \pm 3$ & $138 \pm 3$ & $6.1 \pm 0.3^{*}$ & $6.0 \pm 0.3$ & $11.4 \pm 1.7$ & $11.9 \pm 1.3$ \\
\hline
\end{tabular}

* $\mathbf{P}<0.001$, compared to pre-injection levels in normal rats.

Effects of intracerebroventricular injection of dopamine and metoclopramide in bilaterally nephrectomized rats:

At $10 \mathrm{hr}$ following bilateral nephrectomy, the basal levels of plasma aldosterone were slightly decreased, but these decreases were not statistically significant (Fig. 1 and 2). The basal plasma renin activity was measurable $(0.30 \pm 0.02 \mathrm{ng} / \mathrm{ml} / \mathrm{hr})$ at $10 \mathrm{hr}$ after nephrectomy. There were no responses of plasma renin activity and plasma aldosterone to metoclopramide (Fig. 2), and there was no response of plasma renin activity to dopamine in the nephrectomized rats (Fig. 1). Dopamine, however, showed a tendency to stimulate plasma aldosterone slightly in the nephrectomized rats, but this change in aldosterone was not statistically significant $(0.1>P>0.05) \quad$ (Fig. 1). There were no significant changes in plasma renin activity and plasma aldosterone in the rats which were given $0.9 \%$ saline intracerebroventricularly. Among the 3 groups, there were no significant differences in the basal values of plasma renin activity and plasma aldosterone. However, the basal levels of plasma potassium in the nephrectomized rats were significantly $(\mathrm{P}<0.001)$ higher than those in the normal rats (Table 1). Neither dopamine nor metoclopramide produced any significant change in plasma potassium levels after the injection (Table 1). These compounds similarly produced no significant changes in the plasma sodium and corticosterone levels (Table 1).

In the sham-operated rats, the changes in plasma renin activity and plasma aldosterone after intracerebroventricular injection of dopamine and metoclopramide were similar to those in the normal rats (data not presented here). Furthermore, no significant changes in the plasma sodium, potassium and corticosterone levels were found after the intracerebroventricular injection of these compounds (data not presented here).

\section{Discussion}

In this study, we confirmed the central effects of dopamine and metoclopramide on plasma renin activity and plasma aldosterone in rats. Namely, the intracerebroventricular injection of dopamine into normal rats significantly suppressed plasma renin activity and plasma aldosterone. Furthermore, intracerebroventricular injection of metoclopramide into normal rats significantly elevated plasma renin activity and plasma aldosterone. These results are in good accordance with the previous findings of Kondo 
et al. (1981a and b).

To elucidate the role of the peripheral renin-angiotensin system in the central dopaminergic control of aldosterone secretion, we employed bilaterally nephrectomized rats as a model of the suppressed peripheral renin-angiotensin system in this present study. Intracerebroventricular injections of dopamine and metoclopramide in the nephrectomized rats caused no significant changes in plasma renin activity or plasma aldosterone. These findings suggest that the effects of the intracerebroventricular injection of these drugs on aldosterone secretion may be mediated mainly by the peripheral reninangiotensin system.

Although the possibility exists that dopamine and metoclopramide may escape from the cerebral ventricles into the systemic circulation and there change the plasma aldosterone, the doses employed here were not effective following the peripheral administration. Namely, in preliminary experiments, we found that intravenous administration of dopamine and metoclopramide did not change the plasma renin activity or plasma aldosterone. It is considered therefore that the results of our experiment reflect the central effects of these drugs.

The results of the intracerebroventricular injection of dopamine in nephrectomized rats suggest that the main effect of such intracerebroventricular injection of dopamine on aldosterone secretion may be mediated by the peripheral renin-angiotensin system. However, it is conceivable that another mechanism(s) apart from the peripheral reninangiotensin system may be involved in the central dopaminergic regulation of plasma aldosterone, because in the 6 nephrectomized rats that were injected with dopamine intracerebroventricularly, 4 rats showed an elevation in plasma aldosterone.

Recently, it has been reported that dopamine stimulates cortisol, presumably via $\mathrm{ACTH}$, at a site within the blood-brain barrier in man (Lightman, 1981). In the pre- sent study, we measured the plasma corticosterone before and at $30 \mathrm{~min}$ after the intracerebroventricular injection of dopamine, but we could not find any significant elevation. The role of catecholamines in modulating the secretion of ACTH has been investigated by many workers with conflicting results (Van Loon et al., 1971; Abe et al., 1974). Although we did not measure the plasma concentration of ACTH, our findings concerning plasma corticosterone seem to indicate that, at least at the doses employed in our experiment, dopamine and metoclopramide do not affect the secretion of ACTH. It can be said therefore that intracerebroventricular injection of these compounds has no effect on ACTH secretion following aldosterone secretion.

In addition, we investigated the changes in plasma sodium and potassium. The present data suggest that the plasma sodium and potassium showed no change after the intracerebroventricular injection of dopamine and metoclopramide in normal rats. Furthermore, the plasma potassium levels after bilateral nephrectomy were significantly higher than those in normal rats, but showed no change after the intracerebroventricular injection of dopamine and metoclopramide. Plasma sodium and potassium thus exert no effect on aldosterone secretion in this kind of experiment. However, the higher potassium levels in the nephrectomized rats may exert an effect on the basal levels of plasma aldosterone, because the pre-injection levels of plasma aldosterone in the nephrectomized rats showed no significant differences from those in the normal rats.

The data presented in this study do not clarify the other mechanism(s), except the peripheral renin-angiotensin system modulating plasma aldosterone secretion. However, one possibility which could explain a tendency to elevate plasma aldosterone in nephrectomized rats is that the intracerebroventricular injection of dopamine may stimulate an unidentified, non-ACTH steroido- 
genic factor, as previously suggested by Palmore et al. (1969). These authors also proposed that this factor may be related mainly to the increase in plasma aldosterone in the absence of the kidney, and it is conceivable from our results that such a receptor may not be antagonized by metoclopramide. Indeed, much interest has centered around the possibility that more than one type of dopamine receptor exists (Peringer et al., 1976; Kebabian et al., 1979). It may be concluded therefore that there are at least two different dopamine receptors in the brain, and it can be postulated that a slight elevation of aldosterone secretion in nephrectomized rats after intracerebroventricular injection of dopamine is due to the action of another type of dopamine receptor. Confirmation of this will require further research.

In conclusion, it can be said on the basis of the results of the present study that in the rat the central dopaminergic system may regulate the peripheral renin-angiotensinaldosterone system. Furthermore, from the results obtained by bilateral nephrectomy, the plasma aldosterone secretion after intracerebroventricular injection of dopamine or metoclopramide may occur mainly dependent on the peripheral renin-angiotensin system.

\section{References}

Abe, K. and T. Hiroshige (1974). Changes in plasma corticosterone and hypothalamic CRF levels following intraventricular injection or drug-induced changes in brain biogenic amines in the rat. Neuroendocrinology 14, 195-211.

Carey, R. M., M.O. Thorner and E. M. Ortt (1979). Effects of metoclopramide and bromocriptine on the renin-angiotensin-aldosterone system in man. J. Clin. Invest. 63, 727-735.

Carey, R. M., M. O. Thorner and E. M. Ortt (1980). Dopaminergic inhibition of metoclopramide-induced aldosterone secretion in man. J. Clin. Invest. 66, 10-18.

Dolphin, A., P. Jenner, C. D. Marsden, C. Pycock and D. Tarsy (1975). Pharmacological evidence for cerebral dopamine receptor blockade by metoclop- ramide in rodents. Psychopharmacologia 41, 133138.

Haber, E., T. Koerner, L. B. Page, B. Kliman and A. Purnode (1969). Application of a radioimmunoassay for angiotensin $\mathrm{I}$ to the physiologic measurements of plasma renin activity in normal human subjects. J. Clin. Endocr. 29, 1349-1355.

Hornykiewicz, O. (1966). Dopamine (3-hydroxytyramine) and brain function. Pharmacol. Rev. 18, 925-964.

Kamberi, I. A., R. S. Mical and J. C. Porter (1970). Effect of anterior pituitary perfusion and intraventricular injection of catecholamines and indoleamines on LH release. Endocrinology 87, 1-12.

Kebabian, J. W. and D. B. Calne (1979). Multiple receptors for dopamine. Nature 277, 93-96.

Kondo, K., H. Suzuki, M. Handa, S. Nagahama, T. Yasui, M. Fujimaki, T. Ogihara and T. Saruta (1981a). Central and peripheral effects of dopamine on the renin-angiotensin-aldosterone system in conscious rats. Jpn. Circ. J. 45, 1121-1125.

Kondo, K., A. Ebihara, H. Suzuki and T. Saruta (1981b). Role of dopamine in the regulation of blood pressure and the renin-angiotensin-aldosterone system in conscious rats. Clin. Sci. 61, 235s-237s.

Lightman, S. L. (1981). Studies on the responses of plasma renin activity and aldosterone and cortisol levels to dopaminergic and opiate stimuli in man. Clin. Endocrinol. 15, 45-52.

McCallum, R. W., J. R. Sowers, J. M. Hershman and R. A. L. Sturdevant (1976). Metoclopramide stimulates prolactin secretion in man. J. Clin. Endocrinol. Metab. 42, 1148-1152.

Norbiato, G., M. Bevilacqua, U. Raggi, P. Micossi and C. Moroni (1977). Metoclopramide increases plasma aldosterone concentration in man. J. Clin. Endocrinol. Metab. 45, 1313-1316.

Noth, R.H., R.W. McCallum, C. Contino and J. Havelick (1980). Tonic dopaminergic suppression of plasma aldosterone. J. Clin. Endocrinol. Metab. 51, 64-69.

Ogihara, T., K. Iinuma, K. Nishi, Y. Arakawa, A. Takagi, K. Kurata, K. Miyai and Y. Kumahara (1977). A non-chromatographic non-extraction radioimmunoassay for serum aldosterone. J. Clin. Endocrinol. Metab. 45, 726-731.

Palmore, W.P., N. J. Marieb and P. J. Mulrow (1969). Stimulation of aldosterone secretion by sodium depletion in nephrectomized rats. Endocrinology 84, 1342-1351.

Peringer, E., P. Jenner, I. M. Donaldson, C. D. Marsden and R. Miller (1976). Metoclopramide and dopamine receptor blockade. Neuropharmacology 15, 463-469.

Pinder, R. M., R. N. Brogden, P.R. Sawyer, T.M. Speight and G.S. Avery (1976). Metoclopramide: a review of its pharmacological properties and clinical use. Drugs 12, 81-131.

Salmenperä, M. and A.I. Kahri (1976). Cortico- 
sterone, 18-OH-deoxycorticosterone, deoxycorticosterone and aldosterone secretion in tissue culture of foetal rat adrenals in the presence and the absence of ACTH. Acta Endocrinol. 83, 781-793.

Scanlon, M. F., D. R. Weightman, B. Mora, M. Heath, D. J. Shale, M. H. Snow and R. Hall (1977). Evidence for dopaminergic control of thyrotrophic secretion in man. Lancet 2, 421-423.

Sowers, J.R., E. Sollars, J.D. Barrett and M.P. Sambhi (1980a). Effect of L-dopa and bilateral nephrectomy on the aldosterone response to metoclopramide. Life Sci. 27, 497-501.

Sowers, J.R., M. L. Tuck, M.S. Golub and E. G. Sollars (1980b). Dopaminergic modulation of aldosterone secretion is independent of alterations in renin secretion. Endocrinology 107, 937-941.

Sowers, J.R., M.S. Golub, M. L. Tuck and D.K. Sowers (1981). Role of prolactin and the reninangiotensin system in mediating dopaminergic control of aldosterone secretion in the rat. Clin. Exp. Hypertens. 3, 1-14.

Thorner, M.O. (1975). Dopamine is an important neurotransmitter in the autonomic nervous system. Lancet 1, 662-665.

Van Loon, G. R., L. Hilger, A. B. King, A. T. Boryczka and W.F. Ganong (1971). Inhibitory effect of L-dihydroxyphenylalanine on the adrenal venous 17-hydroxycorticosteroid response to surgical stress in dogs. Endocrinology 88, 1404-1414. 